\title{
EFFECT OF CHLORIDE IONS ON THE ELECTROCHEMICAL BEHAVIOUR OF PLATINUM SURFACES
}

\author{
NAMAL PRIYANTHA* and SARATH MALAVIPATHIRANA \\ Department of Chemistry, University of Peradeniya, Peradeniya.
}

(Received: 01 March 1996; accepted: 04 May 1996)

\begin{abstract}
Platinum electrode surfaces exhibit an unusual behaviour in chloride containing-electrolyte solutions which is different from that in standard buffer systems. Formation of a platinum-chloride complex of an unknown stoichiometry is predicted at anodic potentials. This complex is reduced at a potential more positive than that required for the reduction of the surface platinum oxide.
\end{abstract}

Key words: Chloride, cyclic voltammetry, electrochemistry, platinum.

\section{INTRODUCTION}

Interfacial electrochemistry of platinum in aqueous medium is very complicated. Formation of surface oxide and subsequent reduction to form a pure platinum surface, followed by hydrogen adsorption and desorption are usually observed in aqueous medium. ${ }^{1-3}$ The appearance, current and potential of voltammetric peaks associated with these processes depend strongly on experimental conditions such as solution $\mathrm{pH}$, nature of the electrolyte and nature of the medium.

The use of platinum is becoming increasingly popular due to its unique advantages. Platinum is known to be an effective catalyst for a variety of reactions including the reduction of nitric acid by ammonia, ${ }^{4}$ the electrochemical generation of hydrogen and the reduction of oxygen. ${ }^{5}$ Platinum family metals are also considered to be valuable elements in medical technology as several newly synthesized organo-platinum and organo-palladium complexes show antitumour and antimicrobial properties. ${ }^{6,7}$ Use of 195-Pt nuclear magnetic resonance spectroscopy for irivestigation of platinum levels in electroplating baths, ${ }^{8}$ and the use of platinum as an active electrode material in fuel cells ${ }^{9,10}$ are also considered as exciting applications. Furthermore, platinum electrodes have been employed in the construction of analytical sensors for substances in gas/liquid phases. ${ }^{11,12}$

It is of importance to understand the type and extent of interactions between platinum surfaces and solution species. Such interactions depend on the reactivity of the species and surface characteristics of the electrode. However, the effect of neutral electrolytes and mixed solvent systems on electrochemical measurements has been rarely studied. Consequently, there is no generalized

" Corresponding author. 
model available to explain such interactions although both electrochemical and spectroscopic investigations are employed for individual electrochemical systems. ${ }^{13,14}$

In this study, interfacial behaviour of polycrystalline platinum surfaces in an aqueous medium is reported. Special attention is given to characterize the effect of chloride species on the voltammetric behaviour of platinum. This system has been specially selected because chloride electrolytes are commonly used in a variety of electrochemical systems. The effect of solution $\mathrm{pH}$ and the starting potential on the voltammetric behaviour of platinum in the presence of chloride ions is also discussed.

\section{METHODS AND MATERIALS}

Materials: Electrolytes: lithium chloride (Vickers, England), sodium chloride (Vickers, England), potassium chloride (Vickers, England), phosphoric acid (BDH, England) and hydrochloric acid (Avondale Laboratories, England) were analytical grade and used as received. Sodium hydroxide (Park, England) was used to adjust the solution $\mathrm{pH}$ as necessary. All electrolyte solutions were prepared in freshly distilled water. Deaeration of the solution in the electrochemical cell was accomplished by sparging with nitrogen before all experiments.

Instrumentation: All electrochemical experiments were conducted in a onecompartment three electrode cell system consisting of a platinum disk working (Bioanalytical Systems, USA), a saturated calomel (SCE) reference and a platinum wire counter electrode. The platinum working electrode was polished with alumina and rinsed thoroughly with distilled water prior to each experiment. All cyclic voltammetric experiments were performed with an Oxford Instruments potentiostat and recorded on a Yew Instruments Model $3022 \mathrm{X}-\mathrm{Y}$ recorder. All potentials were reported with respect to SCE.

\section{RESULTS}

Cyclic voltammetric studies of polycrystalline platinum electrodes in phosphate buffer $(\mathrm{pH}=7)$ show the expected behaviour of a bare electrode. Electrochemical processes such as adsorption/desorption, and the formation of platinum oxide and subsequent reduction are clearly observed. Voltammetric experiments conducted at initial potentials which were changed by $0.1 \mathrm{~V}$ steps (from $+0.1 \mathrm{~V}$ to $+1.0 \mathrm{~V}$ ) indicated that oxidation of the platinum surface in the phosphate buffer occurs at potentials greater than $+0.5 \mathrm{~V}$ (Fig. 1a). The corresponding reduction peak disappears and the peak current of the hydrogen adsorption/ desorption region becomes negligible if the voltammetric experiments are started below this potential. 


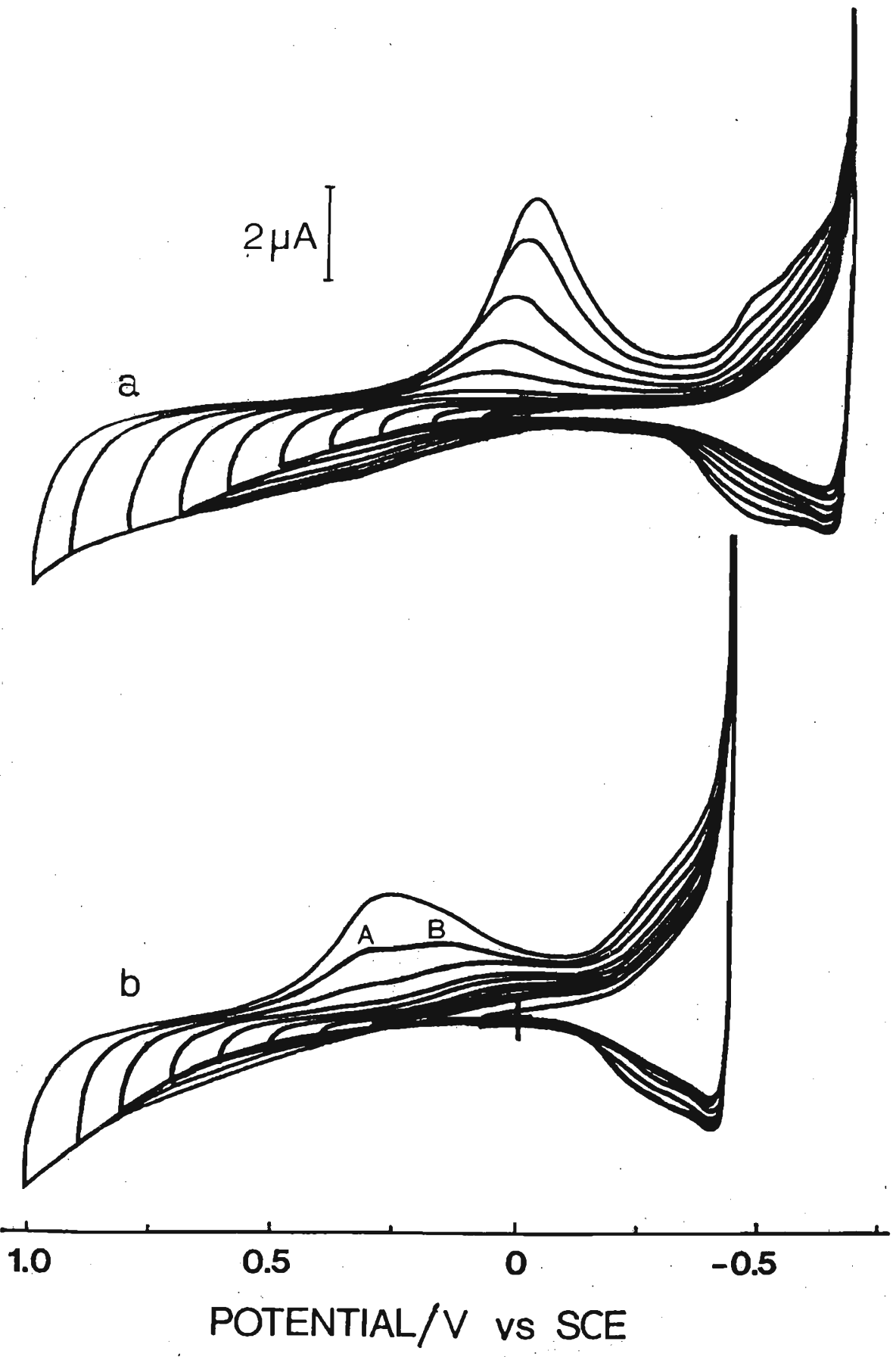

Figure 1: Cyclic voltammograms of bare platinum electrode in $0.1 \mathrm{M}$ phosphate buffer under $\mathrm{N}_{2}$ saturation. Scan rate $100 \mathrm{mV} \sec ^{-1}$. (a) $\mathrm{pH}=7$ (b) $\mathrm{pH}=3$. 


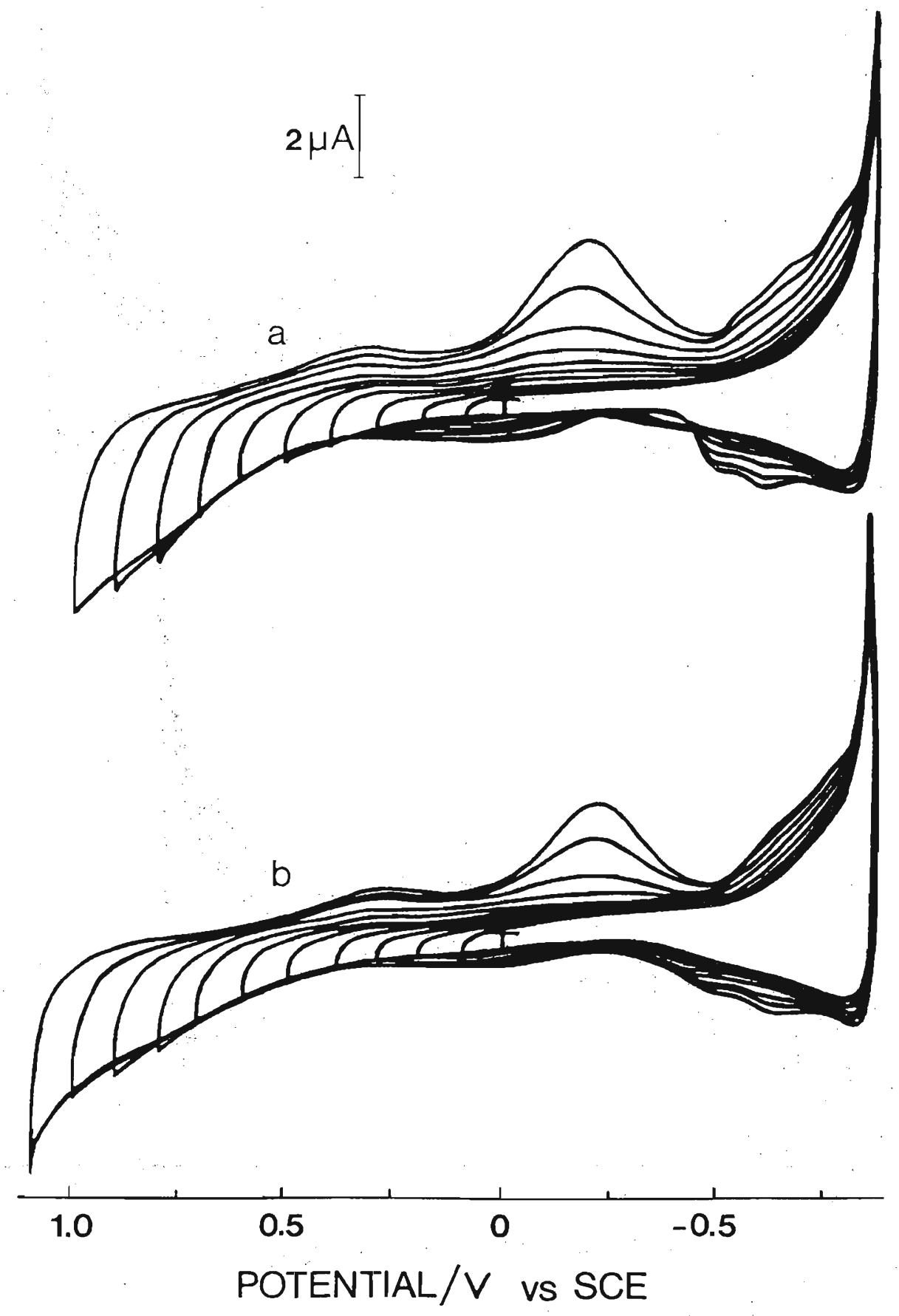

Figure 2: Cyclic voltammograms of bare platinum electrode under $\mathbf{N}_{2}$ saturation in (a) $0.1 \mathrm{M} \mathrm{NaCl}$ (b) $0.1 \mathrm{M} \mathrm{KCl}$. Scan rate $100 \mathrm{mV} \mathrm{sec}^{-1}$. 

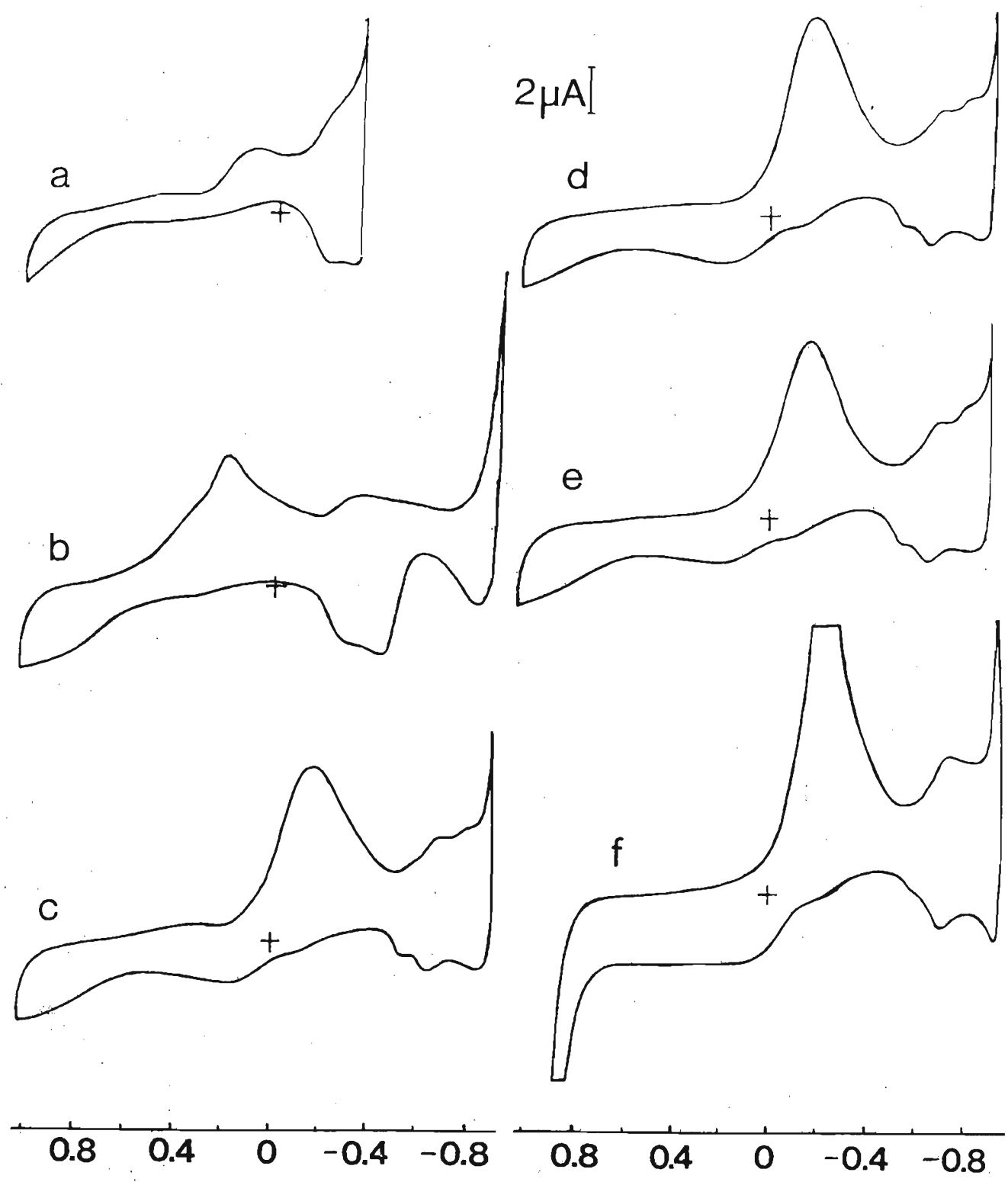
POTENTIAL/V vS SCE

Figure 3: Cyclic voltammograms of bare platinum electrode in $\mathrm{HCl}$ solutions by additions of $\mathrm{NaOH}$ under $\mathrm{N}_{2}$ saturation. Scan rate $100 \mathrm{mV} \mathrm{sec}{ }^{-1}$. The $\mathrm{pH}$ of the solution (a) 1.0 (b) 3.0 (c) 5.6 (d) 7.0 (e) 9.0 (f) 11.0 . 
The effect of the change in solution $\mathrm{pH}$ on the voltammetric behaviour (in buffered systems) is interesting. The platinum oxide reduction peak is actually a combination of two peaks, although it appears as a single peak when the starting potential is high. In the phosphate buffer system of $\mathrm{pH} 3$, the two peaks (A and $\mathrm{B}$ ) are resolved if the starting potential is kept below $+0.9 \mathrm{~V}$ (Fig. 1b). Cyclic voltammetric scans of a bare platinum electrode in chloride electrolytes ( $\mathrm{LiCl}, \mathrm{NaCl}$ and $\mathrm{KCl}$ ) show a different behaviour compared to that in the buffered systems discussed earlier. A new reduction peak appears at a potential, which is $0.5 \mathrm{~V}$ more positive than the platinum oxide combined peak of reduction (Fig. 2).

Further studies of platinum electrodes in $0.1 \mathrm{M} \mathrm{HCl}$ electrolyte solutions at different $\mathrm{pH}$ values gave an insight to the platinum chloride complex formation. The reduction peak associated with the complex formation was observed at about $+0.4 \mathrm{~V}$ and the peak potential was not changed when the $\mathrm{pH}$ of the medium was increased by the addition of a strong base, concluding that there is no involvement of $\mathrm{H}^{+}$or associated species for the appearance of this peak (Fig. 3).

\section{DISCUSSION}

The presence of two peaks in Fig. $1 \mathrm{~b}$ is probably associated with the formation of two types of surface platinum oxides formed during the potential scan towards the positive potentials. The current of peak $\mathrm{A}$ is enhanced with increasing starting potential, concluding that the platinum oxide complex that leads to peak $\mathrm{A}$ is formed at higher potentials and the platinum oxide associated with the other peak (peak B) is formed at lower values. It has been pointed out that the formation of surface oxide is a complicated process and that there are several types of surface oxides. ${ }^{15}$ The resolution of the two reduction peaks is decreased with increasing $\mathrm{pH}$. Furthermore, the currents associated with hydrogen adsorption/desorption processes are increased with increasing $\mathrm{pH}$ showing the strong influence of the acidity on these processes. In all cases, two distinct reduction and oxidation peaks were observed in the hydrogen adsorption/ desorption region as reported elsewhere. ${ }^{16}$

It is proposed that the new reduction peak observed in the chloride electrolyte systems is associated with the reduction of the platinum-chloride complex of unknown stoichiometry, which is formed when the platinum electrode is given an oxidative potential scan. Such a complex is probably formed by adsorption of chloride species to platinum atoms, which are at an excited state at high positive potentials. Alternatively, molecular chlorine, the oxidation product of chloride, forms a complex with platinum atoms through chemisorption. The potential required for the formation of this complex is higher than that required for common platinum oxide formation, because the new reduction peak is observed when the starting potential is greater than $+0.6 \mathrm{~V}$. Platinum is well known for 
the formation of complexes with anions and electron donating species. The formation of platinum-methanol and platinum-pyridyl complexes have already been reported.$^{3}$

The decrease in the current of the new reduction peak and the increase in the current of the platinum oxide reduction peak with increasing $\mathrm{pH}$ (Fig. 3) leads to the conclusion that there is an equilibrium between chloride and hydroxide anions present in the medium. Similar equilibrium between acetate and hydroxide ions has already been observed earlier. ${ }^{17}$ The following mechanism may explain the proposed equilibrium between the solution anions:-

Equilibrium process

$$
\mathrm{PtCl}_{\mathrm{n}}+\mathrm{nOH}^{-} \rightleftharpoons \mathrm{Pt}(\mathrm{OH})_{\mathrm{n}}+\mathrm{nCl}^{-}
$$

First electrochemical reduction (new peak)

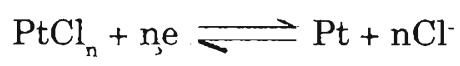

Siecond electrochemical reduction (combined peak)

$$
\begin{aligned}
& \mathrm{Pt}(\mathrm{OH})_{\mathrm{n}}+\mathrm{nH}^{+}+\mathrm{ne} \rightleftharpoons \mathrm{Pt}+\mathrm{nH}_{2} \mathrm{O} \text { (acidic medium) } \\
& \mathrm{Pt}(\mathrm{OH})_{\mathrm{n}}+\mathrm{ne} \rightleftharpoons \mathrm{Pt}+\mathrm{nOH}^{-} \text {(basic medium) }
\end{aligned}
$$

Such studies would be of great significance in order to understand the reactivity of platinum surfaces in electrochemical reactors, including fuel cells and chromatographic systems. It would be difficult to optimize reaction conditions of such systems, if a complete understanding of the electrochemical behaviour in simple electrolyte solutions is not available. Electrochemical characterization of bare platinum surfaces in mixed aqueous/nonaqueous solvent systems that are commonly used in liquid chromatographic separations would be the next logical step in this work.

\section{References}

1. Hubbard A.T. (1980). Electrochemistry of well defined surfaces. Accounts of Chemical Research 13: 177-184.

2. Ghoneim M.M., Clouser S. \& Yeager E. (1985). Oxygen reduction kinetics in deuterated phosphoric acid. Journal of Electrochemical Society 132: 11601162. 
3. Root D.P. \& Priyantha N. (1988). Electroinactive coatings on platinum electrodes in aqueous solution. Journal of Electroanalytical Chemistry 257: 231-237.

4. Lintz H.G. \& Oerter M. (1993). The platinum catalyzed reduction of nitric oxide by ammonia. Platinum Metals Review 37: 8-13.

5. Kao W.H. \& Kuwana T.(1984). Electrocatalysis by electrodeposited spherical $\mathrm{Pt}$ microparticles dispersed in a polymeric film electrode. Journal of American Chemical Society 106: 473-476.

6. Hartwig J.F., Pil P.M. \& Lippard S.J. (1992). Synthesis and DNA-binding properties of a cisplatin analogue containing a tethered dansyl group. Journal of American Chemical Society 114: 8292-8293.

7. Warner Lambert Company, New anti-microbial and anti-neoplastic platinum complexes. US Patent 5: 116, 831.

8. Levason W. \& Pletcher D. (1993). 195-Platinum nuclear magnetic resonance spectroscopy. Platinum Metals Review 37: 17-23.

9. Staschewski D. (1992). Hydrogen-air fuel cells of the alkaline matrix type: manufacture and impregnation of electrodes. International Journal of Hydrogen Energy 17: 643-649.

10. Passalacqua E., Antonucci P.L., Vivaldi M., Patti A, Antonucci V., Giordano N. \& Kinoshita K. (1992). The influence of Pt on the electrooxidation behaviour of carbon in phosphoric acid. Electrochimica Acta 37: 2725-2730.

11. Hughes S., \& Johnson D.C. (1981). Amperometric detection of simple carbohydrates at platinum electrodes in alkaline solutions by application of a triple-pulse potential waveform. Analytica Chimica Acta 132: 11-22.

12. Lei Y.J. (1993). Sensors for toxic gas detection. Platinum Metals Review 37: $146-150$.

13. Caram J.A., \& Gutierrez C. (1992). Cyclic voltammetric and potentialmodulated reflectance spectroscopic study of the electroadsorption of methanol and ethanol on a platinum electrode in acid and alkaline media. Journal of Electroanalytical Chemistry 323: 213-230. 
14. Papoutsis A., Leger J.M. \& Lamy C. (1993). Study of the kinetics of adsorption and electro-oxidation of $\mathrm{MeOH}$ on $\mathrm{Pt}(100)$ in an acid medium by programmed potential voltammetry. Journal of Electroanalytical Chemistry 359: 141160.

15. Chao T. Walsh K.J. \& Fedkiw P.S. (1991). Cyclic voltammetric study of the electrochemical formation of platinum oxide in a Pt/yttria-stabilized zirconia cell. Solid State Ionics 47: 277-285.

16. Bard A.J.\& Faulkner L.R. (1980). Electrochemical methods. Wiley, New York.

17. Root D.P. \& Priyantha N. (1991) Acetate adsorption and metal overlayers on electrode surfaces. Electrochimica Acta 36: 2109-2112. 